Faustos Pós-Modernos: conhecimento em rede.

Revista Ensaios, vol. 13, jul-dez de 2018. ISSN 2175-0564.

\title{
Faustos Pós-Modernos: conhecimento em rede
}

\author{
Flavio Fonte-Boa ${ }^{1}$
}

Resumo: O mito de Fausto, o cientista "amaldiçoado" pelo conservadorismo religioso contra seu substitutivo método experimental de acessar o mundo, revela a resistência social à livre circulação de ideias. Residiria no mundo virtual a chave libertadora dos monopolistas do conhecimento? A inovação intelectual em uma dinâmica sem precedentes coloca em xeque as formas tradicionais de transmissão de informação e desafia pesquisadores quanto a construção do conhecimento neste universo colaborativo. Evolutivamente construímos a interação mediada por meio técnico, no qual ocorre a virtualização das relações com a ampliação dos horizontes e a redução da contextualização. As ilusões das novas ferramentas de acesso à informação levam ao entendimento primordial de "conhece-te a ti mesmo" ou ao engodo do "Oráculo de Delfos". Não sem implicações, investidos de avatares heroicos, navegamos solitariamente pelo virtual coletivamente partilhado, guiados por buscas de certezas que se constroem e se dissolvem aceleradamente.

Palavras Chave: Conhecimento; Internet; Cibercultura.

\section{Web Knowledge: Postmodern Fausts}

\begin{abstract}
The myth of Faust, the scientist "cursed" by religious conservatism against his substitutionary experimental method of accessing the world, reveals the social resistance to the ideas free circulation. Could the virtual world be the key to free of the knowledge monopolists? Intellectual innovation in unprecedented dynamics puts in check the traditional forms of information transmission and challenges researchers as to the construction of knowledge in this collaborative universe. We evolve technically mediated interaction, in which virtualized relationships occur with the expansion of horizons and the reduction of contextualization. There an illusion that new tools to access information could lead to the primordial understanding of "know thyself" or the deception of the "Oracle of Delphi". Not without implications, we dressed with heroic avatars, solitarily surf by the collectively shared virtual world, guided by compasses that search for certainties that are built and destroyed quickly.
\end{abstract}

Keywords: Knowledge; Internet; Cyberculture.

\footnotetext{
${ }^{1}$ Universidade Federal de Minas Gerais (UFMG), Programa de Pós-graduação em Educação (PPGE), Belo Horizonte, MG, Brasil. coiotekk@gmail.com.
} 
Faustos Pós-Modernos: conhecimento em rede.

Revista Ensaios, vol. 13, jul-dez de 2018. ISSN 2175-0564.

Eu estou em todo lugar, sei sobre tudo, portanto eu posso tudo, quem sou eu? Seria Deus, a humanidade, o Google, ou seria Mefistófeles. Existe a chance de que saibamos quem é Mefistófeles, e talvez a essa altura o Google já tenha respondido. Como toda resposta é contextual e toda verdade é transitória por essência, inclusive esta, devemos nos sensibilizar e rever nosso olhar do uso da Internet em toda sua sedução, quanto sua aparente onisciência, onipresença, e onipotência, proporcionada pelo livre acesso à informação e seu potencial na criação de conhecimento.

Não é sem argumentos que a rede de livre acesso à informação desperta um pensamento otimista quanto às suas novas potencialidades. O filósofo Pierre Lévy (1999 p.146) acreditava com razão que hoje esse "metamundo virtual ou ciberespaço irá tornar-se o principal laço de comunicação, de transações econômicas, de aprendizagem e de diversão das sociedades humanas", em sua visão postula questões prioritariamente sobre as novas relações com o conhecimento, propiciadas por tal suporte interativo. Portanto, não seria exagero, ao analisar as potencialidades técnicas da rede, concluir que sua manifestação nos abre um novo espaço a explorar. Exemplifica-se com a possibilidade de uma visita ao Museu do Louvre, enquanto se escreve um ensaio, e dando-nos a oportunidade de comentar sobre os barcos do Egito antigo com um amigo que supostamente more em Londres. Fato oportuno para obter informações detalhadas sobre a navegação no Egito antigo, que nos traz respeito e autoridade, elementos de poder, nas conversas informais com amigos historiadores, mesmo não sendo desta formação acadêmica. Realmente o uso profícuo do repertório da rede é impressionante, fazendo as metas científicas do conhecimento, da descoberta e da transformação, no limite da busca por onisciência, onipresença e onipotência, estarem aparentemente acessíveis via rede.

Por outro lado, setores conservadores, caracterizados por deter a sabedoria, a liberdade e o poder em relação aos demais, sempre viram com reserva a potencial prática do questionamento inflamável combustível para o conhecimento, hoje catalisada pelo crescimento exponencial da disseminação de informação. O mito de Fausto, construído na Idade Média, tinha por finalidade preservar o monopólio do saber nas mãos dos clérigos (católicos ou protestantes), e advertir ao homem de que ao se libertar para a busca do conhecimento e fazer uso do poder advindo da ciência, o resultado seria fatalmente apenas sofrimento. 
Faustos Pós-Modernos: conhecimento em rede.

Revista Ensaios, vol. 13, jul-dez de 2018. ISSN 2175-0564.

Celebrado por inúmeros escritores e outros artistas, o mito encontra em Goethe (1960) sua maior expressão. Em uma até insultante sinopse que se faz aqui da obra tratada. Explicitase que, no mito, o cientista Fausto celebrou um contrato com o demônio Mefistófeles, se comprometendo a entrega de sua alma em troca de conhecer o mundo e experimentá-lo intensamente. No entanto, por onde passou Fausto encontrou e promoveu infelicidades e no final descobriu-se vítima de sua própria sede de saber ao perder sua amada Gretchen.

\section{Onisciência}

Os três atributos sacralizados onisciência, onipresença e onipotência exclusivos do Criador estão entrelaçados e um potencializa o outro. De forma que o mito, mesmo se referindo mais à onisciência, insufla os demais. Nele existem dois pressupostos evidentes: o desejo de conhecer de Fausto e o monopólio do conhecimento de Mefistófeles. Sem a sede de conhecimento de Fausto e a chave de acesso ao repositório de Mefistófeles, não haveriam sedução, contrato nem mesmo resultado da ação. Mesmo sendo Fausto o cientista "amaldiçoado", fruto da reserva da religião quanto ao conhecimento nos fins da Idade Média, ele resistiu de certa maneira no iluminismo, pois os cientistas reivindicaram para si seu poder e o exerceram em razão do monopólio do conhecimento nos procedimentos acadêmicos, substituindo a Igreja. Ainda hoje, sua sombra paira sobre os mecanismos do saber imediato que funcionam na Internet. Acessar informações infinitas, não constroem por si conhecimentos, estes são feitos internamente em situações enfrentadas ou ao menos simuladas, a armadilha onde reside Mefistófeles vem das promessas dos atalhos à sabedoria. De forma que acessar o conhecimento seja estrategicamente uma tarefa muito onerosa para os que buscam.

Plonski (2001) afirma que a vontade de dominar o conhecimento acompanha a trajetória da civilização humana. Refere-se por exemplo ao fato histórico de que em parcela expressiva dos diálogos pós-Socráticos, Platão (427 a.c) buscava compreender a natureza do conhecimento (episteme) e de seus interpretantes (hermenes), o que gera a grande tradição fillosófica da hermenêutica. O historiador também se refere a fé hindu onde se percebia no conhecimento (jnana) uma das três vias de acesso à divindade. Demo (2010 p. 111) recorda que na saga humana o conhecimento foi tido como disruptivo, considerado na Bíblia como "pecado original, Adão e Eva comeram da árvore do conhecimento e o fizeram porque queriam ser como deuses". 
Faustos Pós-Modernos: conhecimento em rede.

Revista Ensaios, vol. 13, jul-dez de 2018. ISSN 2175-0564.

Com o iluminismo e as estruturações dos estados nacionais ocidentais, foi desvelada a importância do conhecimento aplicado para sua supremacia enquanto sociedades rivais. Hoje o conhecimento se revela eixo estruturante do desempenho de sociedades e organizações, refletindo a constatação de que o estímulo ao conhecimento é determinante para as pessoas lidarem com o ambiente em acelerada transformação e crescente complexidade que caracteriza a vida moderna, distribuído em uma rede universal sua possiblidade se torna presente a cada humano conectado.

A relação humana com o conhecimento se faz tão inerente que Fausto e Mefistófeles se fundem de tal forma que são indissociáveis para a manutenção de sua própria existência. Se em algum momento ser e informação estiveram distantes, com os rompimentos da visão moderna sua segregação se tornou despropositada. Ramberg e Gjesdal (2014) sintetizam bem em um conceito, o expressivo e mutável termo (hermenêutica): sendo aquele que abrange tanto a primeira (da compreensão) quanto segunda ordem (da interpretação) de expressões linguísticas e não linguísticas. Se ocupa este esforço filosófico de aproximar o fato da sua transformação em símbolos de transmissão de informação. Com o romantismo alemão a hermenêutica filosófica volta-se para a comunicação simbólica, a pergunta "Como ler?" se torna "Como é que vamos comunicar a todos?". Heidegger cunha a hermenêutica ontológica que é desenvolvida pelo discípulo Gadamer. Hermenêutica então supera essa relação com a comunicação e passa se referir à vida humana e da existência como tal, ao se evoluir o ser como um interpretante e a partir dessa interpretação se dar todo o senso de realidade humana.

Mostrando-se paradoxal que de um modo de pensamento que enfatiza exatamente o nosso reconhecimento da tradição, inicialmente utilizada com o propósito de elucidar a intensão verdadeira do que se escrevia no passado sobre algo, sirva então, muitas vezes, como um instrumento para uma ruptura deliberada com a mesma tradição. As lições da hermenêutica filosófica representam a inovação intelectual, uma manifestação de auto renovação da tradição, do seu dinamismo em suas potenciais e sucessivas reinterpretações. Apreciando a hermenêutica como uma tradição viva, é fundamentalmente a questão da percepção de um horizonte móvel, envolvendo um fio de diálogo que é uma constante articulação da natureza dinâmica histórica a todo o pensamento humano do agora. Gadamer cunha o significado ontológico para a perspectiva em primeira pessoa, rompendo com as abordagens tradicionais modernas para os problemas de validade, de conhecimento e das relações mente-mundo. (BERNSTEIN, 1983) 
Faustos Pós-Modernos: conhecimento em rede.

Revista Ensaios, vol. 13, jul-dez de 2018. ISSN 2175-0564.

Filósofo da crítica à modernidade, Simmel (2006 p. 61) discorre sobre a necessidade do conhecimento sobre as coisas. Segundo ele é com base nas condições, nas necessidades práticas, na inteligência, no desejo, na criatividade e nos movimentos afetivos, que elaboramos o material que tomamos do mundo e de acordo com nossos propósitos, damos a esses materiais determinadas formas, e apenas com tais formas objetivas esse material é usado como elemento de nossas vidas. Mas na modernidade essas forças e esses interesses se liberam de modo peculiar dos serviços da vida que os haviam gerado e aos quais estavam originalmente presos. Tornam-se autônomos, no sentido de que podem ser separados do objeto do qual originam exclusivamente para seu próprio funcionamento e realização. Todo conhecimento deveria ter um sentido na luta pela existência. Saber o verdadeiro comportamento das coisas tem uma utilidade inestimável para a preservação e o aprimoramento da vida. No entanto o conhecimento não é mais usado a serviço dos propósitos práticos: a ciência tornou-se um valor em si mesma.

Depreende dessa constatação o problema em essência daquela que te responde a tudo nos dias de hoje, a fonte de informações em tempo real chamada Google, nossa "Mefistófeles" da atualidade. A promessa de acesso a informação plena de toda a humanidade não é garantia da geração de conhecimento e da aquisição de sabedoria por seus usuários. Ter ciência de algo só é bom quando lhe ajuda a ter ferramentas para exercer sua humanidade perante o outro, desrespeitar o outro devido a sua ignorância sobre determinado tema, fato recorrente na vida em sociedade, trará mais infelicidades que soluções. É preciso ter a noção clara que os contextos sempre são inusitados, únicos e o uso da informação deve ser aplicado nestes momentos de forma a levar ao conhecimento os sujeitos atuantes naquele contexto, uma vez que não existe o certo a se fazer em cada situação, mas sim o entendimento de um posicionamento sócio técnico negociado entre as partes em cada caso. Na jornada humana na terra sempre existirão mais perguntas que respostas e nunca uma pergunta terá somente uma resposta, o tempo, o espaço e as relações subjetivas se incumbem de criar novas perguntas e transformar todas as respostas dadas previamente.

\section{Onipresença}

A obsessão cartesiana com o cálculo e a objetividade deu origem à crítica que Nietzsche chamou de perspectivismo fato incontornável de que toda e qualquer consciência existe no 
Faustos Pós-Modernos: conhecimento em rede.

Revista Ensaios, vol. 13, jul-dez de 2018. ISSN 2175-0564.

espaço e no tempo sendo constituída nas dimensões cultural, linguística e histórica. Cada sujeito ciente está situado, e este é por si só um fato universal. Subjetividade, portanto, é um resultado direto da capacidade da mente para estar ciente de suas próprias representações. Para o pensador o desenvolvimento da linguagem e da consciência andam de mãos dadas, o humano inventa sinais de comunicação ao tempo que se torna cada vez mais consciente de si. Foi por evoluir como um animal social que o homem adquiriu autoconsciência, a consciência não pertence realmente à existência individual do homem, mas sim à sua natureza social, ao rebanho. (MATUSITZ e KRAMER. 2011).

Ao tratarmos da sensação de onipresença na rede, Eisenberg (2003 p. 494) se mostra inclusive irônico, ao dizer que os nominados internautas, "não vão a lugar algum enquanto navegam na rede". Acredita ser equivocada a concepção da Internet como um espaço, e pelo contrário, na medida em que interações humanas via Internet são completamente independentes do lugar de onde se originam, são desterritorializadas, ou seja, o espaço pouco as determina. Em sua visão a essência do processo de virtualização é a não necessidade de um território demarcado, e não a produção de um novo espaço. Neste sentido e visando interpretar as nuances da comunicação o autor recorre aos ensinamentos de Thompson (1995), que postulou que inicialmente temos as interações não mediadas tecnicamente, denominada interação face a face, em que todos são, simultaneamente, produtores e receptores de mensagens, e pela multiplicidade de formas simbólicas que, combinando oralidade e teatralidade, operam na produção de significação. Evolutivamente construímos a interação mediada por meio técnico, como no caso da carta ou do telefone, onde ocorre a desterritorialização (ou virtualização) da interação. Perde-se aí a multiplicidade de formas simbólicas na produção da significação, já que toda a teatralidade contextual desaparece da produção da significação. Talvez o mais central entendimento para o autor, é que no distanciamento espaço-temporal ocasionado pela mediação técnica, opera simultaneamente na ampliação dos horizontes e na redução da identificação da comunidade circunscrita a um contexto.

No extremo das possibilidades introduzidas pela virtualização do espaço na Internet, assumimos o risco ao praticar ao máximo a individualidade possível pelo novo meio. Assim acabando como o que ressalta Sunstein (2002, p. 509) por criar um mundo onde todos acessam somente o que lhes convém, voltado incisivamente apenas ao perfil individual, o que implicaria uma drástica redução do conteúdo comum que alimenta as discussões do espaço público 
Faustos Pós-Modernos: conhecimento em rede.

Revista Ensaios, vol. 13, jul-dez de 2018. ISSN 2175-0564.

republicano e a convivência com a diversidade no jogo que opera a construção do bem comum na sociedade. Afinal o espaço que ocupa também deve ser edificado pelos seus habitantes, assim se reconhecendo como tal, viver em outros lugares por acesso mediado está mais para alienação do espaço real do que a onipresença de um cidadão cosmopolita no mundo.

A ideia que deslocamento digital do espaço e tempo se potencializa com o mecanismo hipertextual foi postulado por Marcuschi (1999 p. 22). Para o autor o conhecimento do hipertexto é muito fragmentário, interferindo em sua interpretação devido à dificuldade de se estabelecer coerência, uma vez que não apresenta relações semânticas ou cognitivas imanentes, oferecendo a possibilidade simultânea de múltiplos graus de profundidade ao ligar textos não necessariamente correlacionados. A possibilidade de uma dada posição seguir a qualquer outra, mesmo que não seja relevante nem correlacionada torna o texto deslocado no tempo e espaço. Tal característica aponta que uma leitura proveitosa do hipertexto exige conhecimentos prévios e consciência plena quanto ao objetivo, já que é um permanente convite a vários caminhos, o que pode fazer com que o internauta muitas vezes se perca na infinidade do universo informacional disponível.

Para Gadamer (2002), a aparência inicial de distância e estranheza em si faz emergir como uma função das limitações do nosso próprio ponto inicial de partida. A mudança ou movimento é essencial para que os indivíduos compreendam a verdade como algo além e acima de sua própria perspectiva particular. O sentido de uma mensagem não é algo que possamos entender de uma vez por todas, de maneira que a nossa leitura contribui para a sua história efetiva, aumentando a complexidade e profundidade do seu significado. É algo que existe na interação dialógica complexa entre as distâncias temporais e espaciais, obter conhecimento da informação é ampliar o conhecimento de si mesmo, são dois processos intermináveis, são tarefas essenciais sem ponto final. Gadamer, embora ciente de que nunca poderemos estar no lugar do outro ou partilhar de sua visão, prescreve que deveríamos nos esforçar para fundir nossos horizontes de maneira a aproximar as visões de perspectivas distantes.

O internauta tem de refutar a tendente visão mediada de que se é uma entidade em terceira pessoa que tudo vê, a quem tudo é apresentado de forma clara e explícita sem ser partícipe. Ele e o outro a quem se relaciona são sujeitos circunscritos em um tempo e espaço e como tal sofrem as influências de seu contexto, e de suas próprias manifestações fenomenológicas na interação 
Faustos Pós-Modernos: conhecimento em rede.

Revista Ensaios, vol. 13, jul-dez de 2018. ISSN 2175-0564.

de dois entes conscientes de si. Todos estão sempre em um espaço e tempo e como tal devem ser atores de sua comunidade, exercendo papel social, intersubjetivo e político na construção evolutiva da ambiência humana local. Sendo efetivos atores de seu espaço-tempo físico, tanto na interpretação do passado quanto na imobilização do legado para o futuro.

\section{Onipotência}

A linguagem precisa, cada vez mais, é um produto do desejo de comando, dar ordens para os outros e para a ordenação, em geral, é uma vontade de poder. Os líderes são retóricos. O poder na academia vem de palavras publicadas, palavras de encantamento mágico para formulação mental racional. Mais fragmentação conduz ao poder técnico da precisão para impor a própria vontade. Assim, dividimos tudo em mais e mais palavras, à medidas menores (horas, minutos e segundos), e à vocabulários especializados, neologismos de partes ínfimas de um todo. Como define Michael Crotty (1998) essa objetividade é a visão epistemológica que coisas existem como entidades significativas independentemente de consciência e experiência, que eles detêm a verdade, que reside em si mesmas, como objetos, que a científica e cuidadosa investigação poderia atingir (MATUSITZ e KRAMER. 2011). Acessar a verdade dos objetos é acessar o poder de ditar aos demais o que é e o que não é. Um despotismo promulgado pela objetividade e individualidade extremas, em sua aplicação para se obter valor na sociedade diante da fragilização do outro.

A onipotência é a maior ilusão do mundo capitalista e se verifica como acepção máxima do culto à individualidade desde a modernidade. Como considera Souza e Öelze (2011 p.186) que historicamente o conhecimento e a tecnologia têm sido um trampolim para o acesso ao poder, a Internet aparece na contemporaneidade como chave para o poder ao se encarnar como tecnologia de acesso ao conhecimento, à própria representação de Mefistófeles. Na visão de Demo (2010 p. 112) o ideário da Internet seria de um mundo livre, sem centro, sem controle, se traduzindo na proposta de Holloway (2003 in Demo 2010 p. 112) de mudar o mundo sem tomar o poder, o que sinaliza o entendimento de que a revolução que busca tomar o poder sucumbiria a ele, inevitavelmente o revolucionário que chegasse ao poder tornar-se-ia um novo reacionário, o poder lhe subiria a cabeça na acepção mais popular da observação histórica. 
Faustos Pós-Modernos: conhecimento em rede.

Revista Ensaios, vol. 13, jul-dez de 2018. ISSN 2175-0564.

Para compreender como a modernidade transformou o conhecimento em poder, Szlechter (2007 pp.104-106) se faz valer da obra "Filosofia do Dinheiro" de Simmel (1977), destacando a relação objetiva proporcionada pela sociedade do consumo, onde os sujeitos passam a ser quantificáveis em função dos objetos e a potencialidade de ser meio de adquiri-los ou deles fazer uso. Os objetos assim são personificados, pensamentos se tornam livros, o trabalho se torna máquinas, automóveis adquirem personalidade, alguns são aventureiros, outros esportivos ou elegantes, os objetos não são mais coadjuvantes aos sujeitos em suas necessidades, mas essenciais na construção de identidades individuais. De onde revela Simmel (1977) uma característica da modernidade na polarização entre culto aos objetos frente à decadência da cultura subjetiva.

Jung teve a surpreendente percepção de que algo unia todas as culturas humanas, uma vez que os seus símbolos e mitos eram inacreditavelmente semelhantes em culturas distanciadas por milênios no espaço-tempo, destacam Collin et al (2012 p. 105). O pesquisador partiu da visão de que tais símbolos remontam as experiências que compartilhamos como espécie, conservadas pela história oral em uma memória coletiva humana. Isso é perene em nosso subconsciente, formando o que o pesquisador nomeou de "inconsciente coletivo", sob a forma de "arquétipos" que por vez são modelos organizadores do comportamento social. Depreendese de seu estudo ser inato em cada humano a tendência de encaixar nossas percepções nesses arquétipos pré-formatados para a compreensão de mundo. Assim, os arquétipos funcionam como uma superestrutura prévia compartilhada, onde apenas completamos as lacunas alojando os sujeitos e objetos de nossa experiência. As pessoas também são reinventadas sob a forma de avatares em redes sociais, onde se constroem ilusões de si mesmas, em um olhar perspicaz todos estão felizes, realizados, pujantes, são belos e têm suas qualidades ressaltadas em um mundo utópico, e de outra face perverso com a realidade cotidiana. Arquétipos de consumo são lançados e todos começam seu processo de aproximação, quem você é na série de sucesso mundial? Pessoas são reificadas e passam a ser um perfeito estranho a si e a seus íntimos, cerceadas pela "netiqueta", pois na rede não é lugar de se mostrar fragilizado, humano, todos só precisam do seu sucesso para compartilhar.

Esta característica é reforçada pela formação objetiva do sistema educacional na acumulação de informação sobre as ferramentas úteis à produção sistêmica de forma competitiva em cada aluno. Assim a rede de sujeitos interligados por dispositivos técnicos, 
Faustos Pós-Modernos: conhecimento em rede.

Revista Ensaios, vol. 13, jul-dez de 2018. ISSN 2175-0564.

Internet, acaba por servir mais à circulação de modas a longa distância que ao aprofundamento das relações intersubjetivas. Estes sistemas são cooptados pela indústria cultural da modernidade que transforma a observação natural em produtos do conhecimento passíveis de quantificação e comércio, e deles são criadas necessidades antes inexistentes e agora cobradas como pré-requisitos à socialização. A divisão do trabalho e estratificação social acabam por estabelecer uma sociedade da insatisfação, onde todos sempre podem ter um capital maior em determinado seguimento e se diferenciar como mais essencial ao sistema, contrapondo os sujeitos que competem sempre buscando serem melhor qualificados pela contagem objetiva do que possuem. Assim o sistema se mantém dinâmico em uma eterna tentativa frustrada de inclusão em uma classe com maior propriedade de capital seja intelectual, cultural ou financeiro.

Segundo Tedesco (2007 p. 60) Simmel em sua reflexão quanto à modernidade conceitua a cultura como o processo de interação, aquisição e enriquecimento pessoal pela assimilação e subjetivação do objeto que o circunda, obtendo reconhecimento e valorização por meio dessa materialidade do sujeito. No entanto, em sua visão, esse conceito foi pervertido pelo exagero moderno do culto ao objeto, desencadeando o inusitado fenômeno do objeto se apoderar do sujeito. Para o filósofo isso atrapalha ou mesmo impede as relações intersubjetivas, pela mera falta de reconhecimento do sujeito para além da posse de seus objetos. A acelerada dinâmica social imposta pelo fluxo de transferência do dinheiro, que envolve sua capacidade de simbolizar e transferir valores, aumenta o número de relações intersubjetivas e especializando e assim nos diferenciando em dígitos, tornando assim as relações mais anônimas e objetivas, os novos meios progressivamente aproximam os distantes e distancia os próximos, e assim se dá também a relação face a face, fazendo da cidade grande e anônima um lugar mais sedutor que o reduto familiar da pequena vila.

Ramberg e Gjesdal (2014) destacam o filósofo Derrida, na denúncia de nosso desrespeito pelo outro, quando afirma o pensador que o entendimento é fundamentalmente possibilitado pela ausência, pelas relações de uma palavra a outras palavras dentro da rede sempre evasiva de estruturas que a linguagem é, em última instância. Nossa relação com o discurso do outro não é de respeito e interação mútua, o reconhecimento da verdade possível do ponto de vista do outro tende a encobrir a maneira em que o outro me escapa, a maneira em que o "eu" sempre não reconhece o "tu" em sua diferença constitutiva, nem ao menos vem se esforçando para tal, 
Faustos Pós-Modernos: conhecimento em rede.

Revista Ensaios, vol. 13, jul-dez de 2018. ISSN 2175-0564.

de antemão se acredita como objetivo inatingível e propõe a se expressar de forma impositiva. Ao desfilarmos nos exibindo em grupos de seres não reconhecíveis sem esforços para o entendimento mútuo, acabamos todos anônimos ante o próximo.

Esse anonimato dos sujeitos acaba por valorizar o reconhecimento de seus objetos, fazendo com que o poder emane das posses e do potencial de consumir e induzir aos outros ao consumo, do que da negociação política do espaço público. Em última análise as pessoas buscam no virtual o poder perdido no espaço real, se apropriam de um mundo mais flexível e simulam exercer relevância em avatares construídos no ideário da falta que o mundo consumista exerce sobre todos. O poder dos mestres de RPG, mobilizadores de opinião de redes sociais, sedutores de sites de relacionamento vêm da frustração da dinâmica incompleta da vida atual. E isso interessa e muito a manutenção do status quo onde abastados veem com bons olhos o deslocamento da reivindicação do espaço, da liberdade e dos direitos aos suportes eletrônicos.

Fausto, assim, ao se enveredar pelo acesso pleno do poder do conhecimento se torna refém da realidade montada pela interrelação da sociedade de seu tempo, uma vez que pela argumentação de Kant a realidade tal como a conhecemos depende do funcionamento cognitivo da mente humana, a sociedade determina o que é verdadeiro e falso, o certo e o errado e o que pensamos ser verdade é uma ilusão coletiva da qual ninguém pode escapar. E ainda nunca poderia atingir seu ideário de sabedoria, evidenciam Gori e Stellino (2014), uma vez que Nietzsche foi categórico ao afirmar que o mundo de um indivíduo é apenas uma interpretação entre um número infinito de possíveis interpretações e representações. Para o filósofo a validade de uma posição particular emerge a partir da relação com todas as outras, sem jamais poder assumir um valor estável e definitivo, assim sendo o conhecimento é transitório e só se faz presente quando socializado e validado na inter-relação dos indivíduos.

Demo (2010 pp. 115-116) percebe, ao citar o argumento de Wales (2006), que não se pode negar que muitos entenderam a importância da "autoridade do argumento", em vez do "argumento de autoridade", preferindo uma cidadania que sabe pensar, argumentar e propor consensos abertos à discussão. Sobretudo, verifica que os fundadores da web apreciavam o imprevisível criativamente aberto, enquanto os usuários foram buscando uma estabilização em ambientes fechados de inovação controlada. Atitude também induzida pelo mercado, pois este comercializaria melhor com a segurança da evolução programada. Sendo assim o poder 
Faustos Pós-Modernos: conhecimento em rede.

Revista Ensaios, vol. 13, jul-dez de 2018. ISSN 2175-0564.

revolucionário da Internet passo a passo vai sendo domesticado e conformado ao previsível, ao controlável, se dobrando a sua posição de veículo, de meio e não de espaço público.

Tedesco (2007 p. 60) revela que Simmel acreditava que fatalmente seriam poucos e com muito esforço e sacrifício que conseguiram usufruir do desenvolvimento cultural típico da modernidade sem se deixar levar por suas tendências irracionais de cunho instrumental e material. Somente nesta década que a cibercultura sacralizada no fim do século começa a ser melhor compreendida por críticos da sociedade e dos suportes tecnológicos de comunicação. Seu problema não reside no ideário do conhecimento, da liberdade ou do poder, mas na crença de que podemos possuí-los pelo acesso à informação em rede. Os três cernes dos anseios humanos do iluminismo (presenciar, entender e fazer) servem à humanização da sociedade, tarefa contínua e nunca completa. Fausto, ansiando uma identidade superior, acreditou que elas eram um fim em si mesmas e comprou com sua alma a ilusão que Mefistófeles lhe ofereceu. Na verdade são ideários inatingíveis que devem servir à evolução humana e não à soberba do indivíduo. Após uma vida de buscas e conquistas insatisfatórias Fausto reconhece o momento de pura felicidade que era a oportunidade de melhorar a vida do outro, e então cai morto. O inspirador ensaísta Michel de Montaigne sugeriu que ao sermos sempre parciais em toda nossa existência, o que nos resta é nos enganar que somos plenos, a parcialidade, a incompletude e a impotência são traços de nossa humanidade.

\section{Referências:}

BERNSTEIN, Richard J. Beyond objectivism and relativism: science, hermeneutics, and praxis. Philadelphia: University of Pennsylvania Press. 1983. 284 p.

COLLIN, Catherine; GRAND, Voulla; BENSON, Nigel; LAZYAN, Merrin; GINSBURG, Joannah; WEEKS, Marcus. O livro da Psicologia. Rio de Janeiro: Editora Globo, 2012. 352p.

DEMO, Pedro.. Coisas velhas em coisas novas: novas "velhas tecnologias". Ciência da Informação, v. 39, n. 1 jan./abr. Brasília: 2001. 108-121p.

EISENBERG, José. Internet Democracia e República. DADOS - Revista de Ciências Sociais, Vol. 46, no 3, Rio de Janeiro: 2003. p. 491-511

GADAMER, Hans-Georg. Verdade e método II: complementos e índice. Petrópolis: $2^{\mathrm{a}}$ Ed. Vozes, (Trad.) Ênio Paulo Giachini. 2002. 624 p. 
Faustos Pós-Modernos: conhecimento em rede.

Revista Ensaios, vol. 13, jul-dez de 2018. ISSN 2175-0564.

GOETHE, Johann Wolfgang von. Fausto. (Pref.) Otto Maria Carpeaux. (Trad.) António Feliciano de Castilho. Clássicos Jackson, v.15. São Paulo: W. M. Jackson. 1960. 323p. XXXV Disponível em: <http://www.ebooksbrasil.org/elibris/faustogoethe.html.> Acesso em: 22/12/2016.

GORI, Pietro and STELLINO, Paolo. O perspectivismo moral nietzschiano. n. 34 - vol. I, São Paulo: 2014. p.101-129.

LÉVY, Pierre. Cibercultura. 1999. (Trad.) Carlos Irineu da Costa. São Paulo: Editora 34, 264 p.

MATUSITZ, Jonathan e KRAMER, Eric. A critique of Bernstein's beyond objectivism and relativism: science, hermeneutics, and praxis. Publicação online 29/04/2011. Poiesis Prax. Jun. 2011 291-303p. Disponível em: https://www.ncbi.nlm.nih.gov/pmc/articles/PMC3136698 Acesso em: 23/06/2015

MARCUSCHI, Luiz Antonio. 1999. A. Linearização, cognição e referência: o desafio do hipertexto. Línguas, instrumentos linguísticos. Campinas: Pontes. p. 21-46.

PLONSKI, Guilherme Ary. 2001. Questões tecnológicas na sociedade do (des)conhecimento. Revista Iberoamericana de Ciencia, Tecnología, Sociedad e Innovación, Salamanca, n. 1, set./ dez. Disponível em: http://www.oei.es/historico/revistactsi/numero1/ plonski.htm Acesso em: 13/05/2016

RAMBERG, Bjørn e GJESDAL, Kristin. "Hermeneutics". The Stanford Encyclopedia of Philosophy (Winter 2014 Edition), ed. Edward N. Zalta, 2014. Disponível em: http://plato.stanford.edu/ archives/win2014/entries/hermeneutics. Acesso em 12/05/2015.

SIMMEL, Georg. Filosofia del dinero. Madrid: Alianza Editorial. 1977. 629p.

SIMMEL, Georg. Questões fundamentais da sociologia: indivíduo e sociedade. (Trad.) Pedro Caldas. Rio de Janeiro: Jorge Zahar. 2006. 120p.

SOUZA, Jessé e ÖELZE, Berthold. Simmel e a modernidade. Brasília: UnB, 1998, 23-40 p.

SUNSTEIN, Cass R. 2002. Republic.com. Princeton: Princeton University Press, 236p.

SZLECHTER, Diego. La Figura del Consumidor em la Modernidad: Un análisis simmeliano de las estratégias empresariales de marketing. Atena digital (Espanha), Barcelona: $n^{\circ} 12$, out. 2007, 99-114 p.

TEDESCO, João Carlos. Georg Simmel e as ambiguidades da modernidade. Ciências Sociais Unisinos $\mathrm{n}^{\mathbf{0}}$ 43, janeiro/abril 2007, 57-67 p.

THOMPSON, John Brookshire. The Media and Modernity. Stanford, Stanford University Press, 1995. 324p. 